\title{
PALINOFÁCIES DE UMA SEQUÊNCIA SEDIMENTAR QUATERNÁRIA DA LAGOA PRETA, PARQUE ESTADUAL DO RIO DOCE, MG, BRASIL
}

\author{
YARO MOISÉS PARIZEK SILVA \\ IGC, UFMG, Av. Antônio Carlos, 6627, 31270-901, Belo Horizonte, MG, Brasil. yaro@ ufmg.br
}

KARIN ELISE BOHNS MEYER

CPMTC/IGC, UFMG, Av. Antônio Carlos, 6627, 31270-901, Belo Horizonte, MG, Brasil. bohnsmeyer@yahoo.br

CLAYTON PERÔNICO \& PAULO DE TARSO AMORIM CASTRO

DEGEO/UFOP, Rua Diogo de Vasconcelos, 122,35400-000, Ouro Preto, MG, Brasil. cperonico@yahoo.com.br, paulo_de_tarso@degeo.ufop.br

\begin{abstract}
PALYNOFACIES OF PRETA LAKE QUATERNARY SEDIMENTARY SEQUENCE, STATE PARK OF DOCE RIVER, MG, BRAZIL. This paper presents the results of a palynofacies study from a quaternary core of Preta Lake State Park of Doce River (PERD), MG, Brazil. Preta Lake is situated in the Doce River's Middle Valley lake complex, which consists of around 160 lakes. According to previous studies, the origin of the lake complex is linked mainly to local neotectonics, which can be divided into two phases. The first stage is characterized by E-W dextral transcurrent movements and occurred from the end of the Pleistocene. The second stage of tectonic movements occurred during the Middle Holocene and is characterized by NW-SE extensional regime, which was responsible for the generation of fault-block activity that promoted unevenness and tipping in beds of the tributary channels, acting as dams and thus creating the lakes. The analysis of palynofacies was carried out on 30 samples of a core of $200 \mathrm{~cm}$, dated at the base at 6,620 \pm 110 years BP. The core shows a sedimentary sequence that consists of three facies of clay varying in color: light gray clay at the base, dark gray clay and brown clay toward the top. From the characterization of the particulate organic matter components and the correlation between changes in their percentage, a palynofacies was identified with a predominance of amorphous organic matter-AOM (70-95\%), fungal spores and opaque phytoclasts as subordinate elements. The palynofacies analysis allows us to conclude that: the sedimentary sequence of Preta Lake was deposited in anoxic-desoxic conditions, consistent with a shallow lake, deposited in a lake or paludal environment, due to large amount of AOM and substantial lack of algae and that Preta Lake has likely been in a filling process since $6,620 \pm 110$ years BP.
\end{abstract}

Key words: palynofacies, Holocene, Preta Lake, Doce River State Park.

RESUMO - Este trabalho apresenta os resultados do estudo de palinofácies de um testemunho de sondagem quaternário da lagoa Preta, Parque Estadual do Rio Doce (PERD), MG, Brasil. A lagoa Preta está inserida no complexo lacustre do Médio Vale do Rio Doce, que é constituído por cerca de 160 lagoas. De acordo com estudos prévios, a origem do complexo lacustre está relacionada, principalmente, à neotectônica local, que pode ser dividida em duas etapas. A primeira etapa é caracterizada pela transcorrência dextral E-W e atuou partir do final do Pleistoceno. Já a segunda etapa de movimentações tectônicas ocorreu durante o Holoceno Médio e é caracterizada pelo regime extensional NW-SE, que foi responsável pela geração de falhamentos normais que promoveram desnivelamentos e basculamentos nos leitos dos canais tributários, funcionando como barragens e gerando, desta forma, os lagos. A análise de palinofácies foi realizada em 30 amostras de um testemunho de sondagem de $200 \mathrm{~cm}$, datado na base em $6.620 \pm 110$ anos A.P. O testemunho de sondagem apresenta uma seqüência sedimentar constituída por três fácies de argila de coloração variada, argila cinza claro na base, argila cinza escuro e argila marrom em direção ao topo. A partir da caracterização dos tipos de componentes orgânicos particulados e da correlação entre as variações de seus percentuais, foi possível identificar uma palinofácies com predomínio de matéria orgânica amorfa (MOA,70-95\%), esporos de fungo e fitoclastos opacos como elementos subordinados. A análise de palinofácies nos permite concluir que: a seqüência sedimentar da lagoa Preta foi depositada em condições anóxicas-disóxicas, compatíveis com lâmina de água de pouca profundidade depositada em ambiente lacustre ou paludal, devido a grande quantidade de MOA e ausência significativa de algas, e, que a lagoa Preta esteve, provavelmente, em processo assoreamento desde $6.620 \pm 110$ anos A.P.

Palavras-chave: palinofácies, Holoceno, lagoa Preta, Parque Estadual do Rio Doce-MG. 


\section{INTRODUÇÃO}

A caracterização qualitativa e quantitativa da matéria orgânica particulada contida nos sedimentos e nas rochas sedimentares constitui a análise de palinofácies. Esta técnica visa à identificação dos componentes particulados individuais, a determinação de suas proporções relativas e absolutas, incluindo suas dimensões e seu estado de preservação (Tyson, 1995). O conceito de "palinofácies", introduzido por Combaz (1964) e ampliado por Tyson (1995), é definido como um corpo de rocha sedimentar contendo um conjunto distinto de matéria orgânica palinológica, que reflita condições ambientais específicas ou que possa ser associado com as características das rochas potencialmente geradoras de hidrocarbonetos. Numa abordagem geral, considerando os trabalhos de definição conceitual (e.g., Traverse, 1994; Tyson, 1995; Mendonça Filho, 1999), a matéria orgânica particulada que resta após o processamento palinológico padrão (HF, $\mathrm{HCl}$ ) é referente a três grupos: palinomorfos (esporos, grãos de pólen, algas, zoomorfos, acritarcos e quitinozoários), fitoclastos (bioestruturados ou não bioestrututados) e matéria orgânica amorfa (MOA).

Pouco se sabe sobre a caracterização dos parâmetros de palinofácies em depósitos lacustres de áreas continentais brasileiras que evoluíram sob influência das variações climáticas e tectônicas como é o caso do sistema lacustre do Parque Estadual do Rio Doce (PERD), que vem sofrendo assoreamento progressivo ao longo do Quaternário (e.g. Barbosa \& Kohler, 1981). O principal objetivo deste trabalho é a caracterização da matéria orgânica particulada contida em amostras do testemunho de sondagem da lagoa Preta (LP01), e o uso das palinofácies identificadas na interpretação das condições deposicionais durante a evolução holocênica na lagoa e sua correlação com os eventos os geológicos regionais tais como a neotectônica quaternária.

\section{MATERIAL E MÉTODOS}

Do testemunho de sondagem LP-01 (23k 0760474, 7821971 UTM), coletado com aparelho do tipo vibrocore, na lagoa Preta (Figura 1), foram selecionadas, 30 amostras, ao longo de $200 \mathrm{~cm}$ de profundidade para o estudo de palinofácies (Figura 2).

O tratamento químico das amostras foi realizado no Laboratório de Palinologia do Centro de Pesquisa Manoel Teixeira da Costa, IGC/UFMG, de acordo com os procedimentos palinológicos não oxidantes descritos por Tyson (1995), Mendonça Filho (1999) e Mendonça Filho et al. (2002), que consistem, basicamente, no tratamento com ácido clorídrico e fluorídrico para eliminação da fração mineral e na separação e concentração da matéria orgânica do resíduo mineral com cloreto de zinco.

A fração maior que $6 \mu \mathrm{m}$ foi concentrada para a montagem de lâminas em meio de gelatina glicerinada e Entellan. As lâminas foram depositadas na Palinoteca do Laborató- rio de Palinologia e Palinofácies do Centro de Pesquisa Manoel Teixeira da Costa, IGC/UFMG, sob a numeração MP-Pa 0037 a 0067.

A classificação da matéria orgânica particulada foi realizada em microscopia de luz branca transmitida sob aumentos de 250 e 400x. A intensidade relativa da fluorescência dos componentes da matéria orgânica foi avaliada com o uso de luz azul incidente no microscópio Olympus BX-51 do Laboratório de Palinologia e Palinofácies do Centro de Pesquisa Manoel Teixeira da Costa, IGC/UFMG.

$\mathrm{Na}$ caracterização da intensidade de fluorescência da matéria orgânica foram atribuídos valores, que variam de 1 a 6, de acordo com a escala numérica de Tyson (1995).

Foi efetuada uma contagem de palinofácies, considerando toda a matéria orgânica particulada até 500 partículas, visando à determinação da frequência relativa dos diferentes componentes da matéria orgânica particulada.

\section{Análise de palinofácies}

O estudo de palinofácies consistiu da análise qualitativa e quantitativa dos diferentes componentes da matéria orgânica particulada, baseado no sistema de classificação proposto por Tyson (1995), com adaptações introduzidas pela primeira vez no Brasil por Mendonça Filho (1999). Estas adaptações a classificação proposta por Tyson (1995) foram sistematizadas nas publicações de Mendonça Filho et al. (2002) e Menezes et al.(2008) e foram adotadas em outros trabalhos de palinofácies no Brasil (e.g. Menezes, 2002; Meyer et al., 2005, 2006). Os componentes orgânicos particulados identificados podem ser vistos na Figura 2. De acordo com esta classificação, a matéria orgânica particulada é referente a três grupos: palinomorfos, fitoclastos e matéria orgânica amorfa (MOA), e, cada um destes três grupos principais é subdividido de acordo com características como tamanho das partículas, estado de preservação, coloração, entre outros. Esta caracterização, o mais detalhada possível possibilita identificar caracteres relacionados ao estado de preservação, transporte e origem biológica dos componentes orgânicos particulados, dentre outros, permitindo inferências sobre as condições ambientais nos ambientes de sedimentação.

Os palinomorfos foram divididos em esporomorfos, de origem terrestre (esporos e grãos de pólen), microplâncton de parede orgânica (algas e cianobactérias), zoomorfos (ovos de platelmintos) e esporos de fungos.

Os fitoclastos foram classificados em opacos (de coloração preta até nas porções marginais da partícula) e não-opacos (de coloração amarela escura a marrom). Os fitoclastos não-opacos e opacos foram subdivididos em categorias de acordo com sua morfologia, presença ou ausência de elementos estruturais, e, estado de preservação. O primeiro grupo dos fitoclastos está representado por fitoclastos opacos equidimensioniais, alongados, corroídos e bioestruturados.

Os fitoclastos não-opacos foram classificados em fitoclastos não-opacos bioestruturados estriados, cutículas 
e fitoclastos não-opacos não bioestruturados. Os fitoclastos não-opacos bioestruturados estriados têm sua origem em tecidos de vegetais superiores e, quando observados em luz branca transmitida, apresentam coloração em diversas tonalidades de marrom, com contornos angulares a levemente corroídos.

As cutículas, que são fragmentos da epiderme de folhas de vegetais superiores, apresentam coloração amarela e marrom, com excelente preservação das estruturas celulares características das epidermes. Em geral, as cutículas se apre- sentam não degradadas, com contornos nítidos. Os fitoclastos não-opacos e não bioestruturados são partículas que não possuem estrutura botânica interna, de coloração marrom-clara, equidimensionais quanto à forma, com contornos nítidos ou levemente irregulares e lascados.

A MOA é caracterizada pela ausência de estruturação, contorno irregular e matriz granular heterogênea. Ocorre sob a forma de grumos ou dispersa, com diferentes tonalidades de marrom, quando analisada sob microscopia óptica de luz branca transmitida.

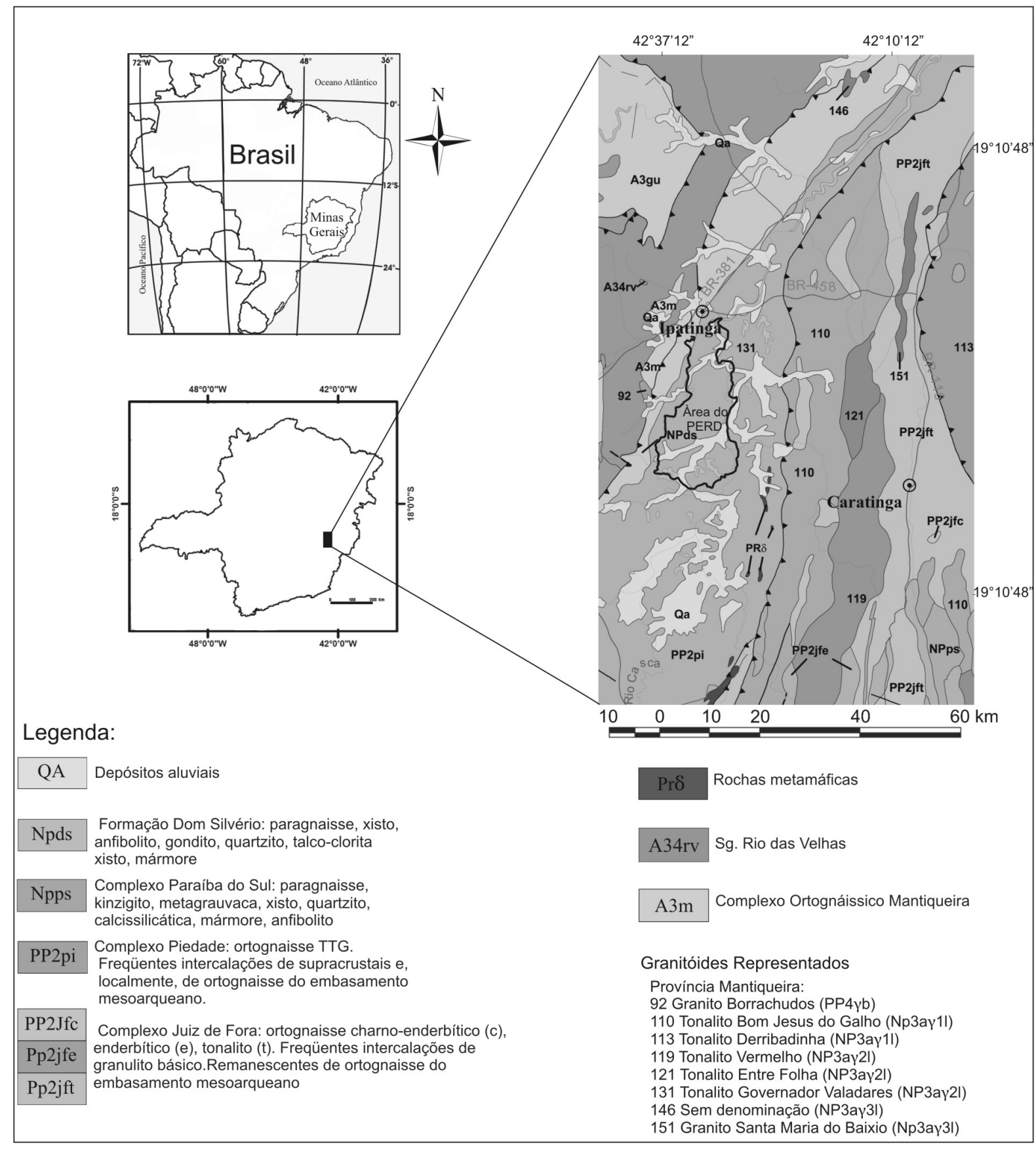

Figura 1. Mapa de localização da lagoa Preta e do testemunho de sondagem LP-01, Parque Estadual do Rio Doce, MG, Brasil (modificado de Heineck et al., 2003).

Figure 1. Location map of Preta Lake LP-01 core, Rio Doce Park, Minas Gerais State, Brazil (modified from Heineck et al., 2003). 


\section{ASPECTOS FÍSICOS E SEDIMENTOLÓGICOS}

O Parque Estadual do Rio Doce (PERD) abrange uma área de 36970 ha nos municípios de Timóteo $(14,1 \%)$, Marliéria $(83,3 \%)$ e Dionísio (2,6\%) (MG). O Parque situa-se no trecho médio do Vale do Rio Doce (1948'18" - 19²9'24" S; $\left.42^{\circ} 38^{\prime} 30^{\prime \prime}-42^{\circ} 28^{\prime} 18^{\prime \prime} \mathrm{W}\right)$, sudeste do Estado de Minas Gerais, e, é considerada a maior área contínua de Mata Atlântica do estado e uma das principais reservas de proteção da biodiversidade.

O complexo lacustre do PERD está inserido na grande área fisiográfica denominada depressão interplanáltica do Rio Doce, e, está confinado entre as elevações correspondentes ao planalto reverso da Serra do Mar (Figura 1).

A lagoa Preta faz parte do complexo lacustre do Médio Vale do Rio Doce, que é constituído por cerca de cento e sessenta lagoas, sendo que aproximadamente quarenta delas estão localizadas dentro do PERD, ocupando uma área de $6 \%$ do total do Parque. Algumas destas lagoas estão em processo de assoreamento.

Os depósitos quaternários provenientes destes lagos constituem seqüências sedimentares caracterizadas, em geral, pelo empilhamento de três fácies que são assim caracterizadas da base para o topo: fácies de aluvião do antigo leito do Rio Doce, fácies marginal-lacustre e fácies lacustre.

As fácies de aluvião do antigo leito do Rio Doce são formadas por depósitos datados até cerca de 9000 anos A.P., depositadas pelo barramento do antigo leito do Rio Doce e seus tributários que deu início a formação dos lagos. Acima das fácies de aluvião, as fácies marginal-lacustre, consistem em sedimentos holocênicos depositados a partir 8500 anos A.P. No topo das seqüências sedimentares as fácies lacustres holocênicas depositadas num ambiente efetivamente lacustre. Estas seqüências estão localizadas sobre um embasamento de gnaisses variados, micaxistos, quartzitos e granitos, que afloram nas elevações do planalto circundante à depressão do médio Rio Doce (Albuquerque, 1998).

Desta forma, podemos posicionar os sedimentos da lagoa Preta, analisados neste estudo, e, que apresentaram na base da seqüência sedimentar uma idade de 6620 \pm 110 anos A.P., na fácies lacustre, que caracteriza a evolução dos corpos lacustres holocênicos do PERD.

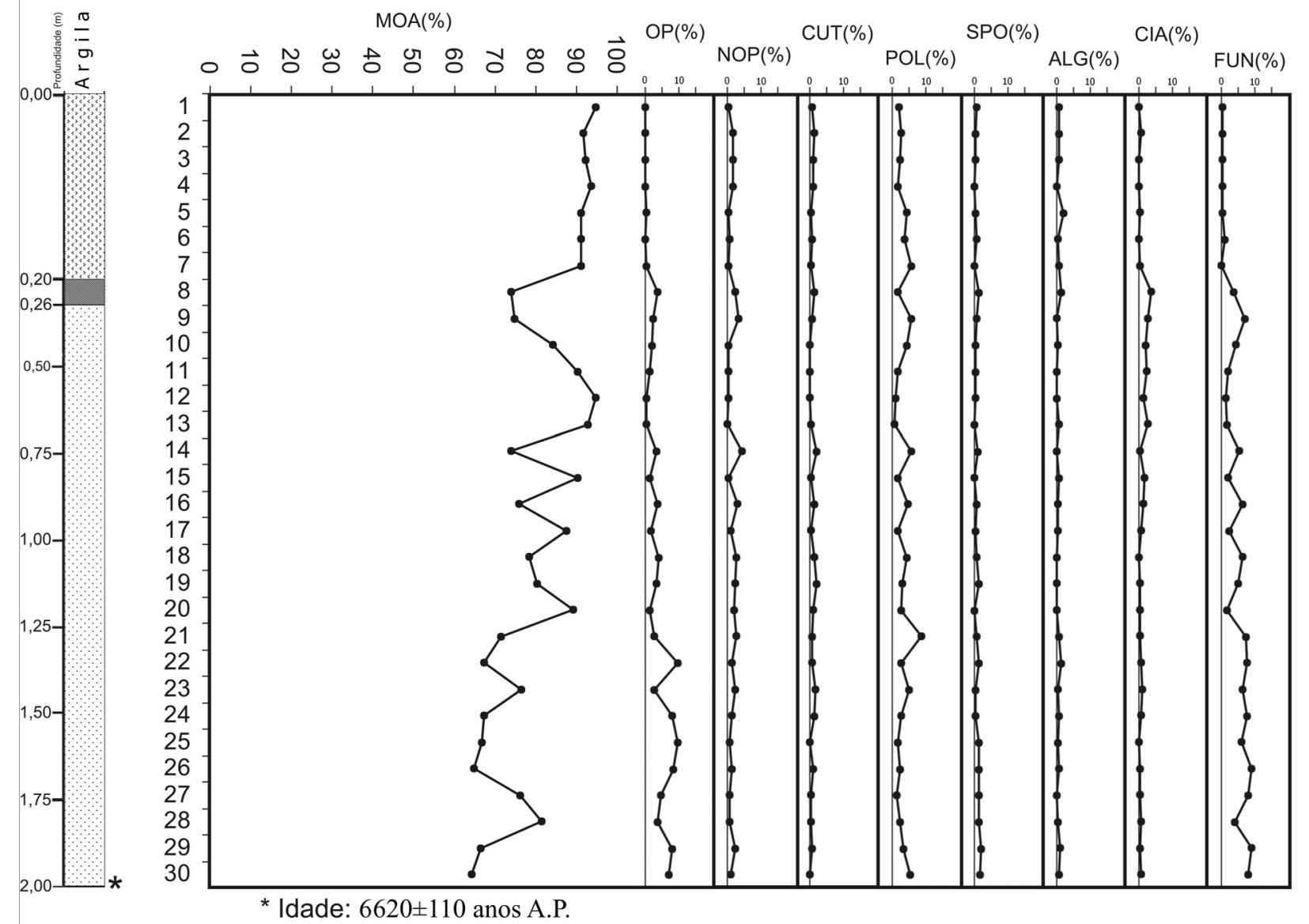

Figura 2. Perfil estratigráfico do testemunho de sondagem LP-01 e frequência absoluta dos componentes da matéria orgânica particulada nas amostras do testemunho LP-01. Abreviações: MOA, matéria orgânica amorfa; OP, fitoclastos opacos; NOP, fitoclastos não-opacos; CUT, cutículas; POL, grãos de pólen; ESP, grãos de esporos; ALG, algas; CIA, cianobactérias; FUN, esporos de fungo.

Figure 2. Stratigraphic profile of LP-01 core and frequency of particulate organic matter in LP-01 core samples. Abbreviations: AOM, amorphous organic matter; OP, opaque phytoclasts; NOP, non opaque phytoclasts; CUT, cuticles; POL, pollen grains; ESP, spores; ALG, algae; CIA, Cyanobacteria; FUN, fungal spores. 


\section{CONTEXTO GEOLÓGICO E NEOTECTÔNICO}

O mapa geológico do Estado de Minas Gerais (Heineck, 2003) mostra que na região do Parque Estadual do Rio Doce existem depósitos aluviais quaternários depositados sobre o Complexo Paleoproterozóico Piedade, composto por ortognaisses. Aparecem também, sob forma de intrusões no Complexo Piedade, granitóides neoproterozóicos da Província Mantiqueira (Tonalito Bom Jesus do Galho e Tonalito Governador Valadares) e rochas metamáficas.

O surgimento dos lagos do Parque Estadual do Rio Doce, situados $20 \mathrm{~m}$ acima do nível do rio e sem conexão com o sistema fluvial, era considerado, até recentemente, como resultado da influência das alternâncias climáticas do Quaternário. No entanto, o levantamento dos abalos sísmi$\cos$, das falhas e dos dados geomorfológicos da região mostram que os movimentos da crosta ocorridos a partir do final do Pleistoceno foram os principais fatores que influenciaram o represamento dos lagos (Mello, 1997).

Barbosa \& Kohler (1981), Saadi (1991) e Suguio \& Kohler (1992) discutiram alguns aspectos geomorfológicos e os consideram importantes indicadores do controle neotectônico na evolução do sistema de lagos. Dentre eles destacam-se: os alinhamentos dos lagos; formatos retilíneos de suas margens; existência de paleovales preenchidos; e presença de direções de lagos associadas a migrações fluviais abruptas.

Os registros sedimentares da área evidenciam duas fases tectônicas distintas. Uma fase de transcorrência dextral E-W, atuante a partir do final do Pleistoceno, que, está relacionada às estruturações NW-SE na rede de drenagem e ao entulhamento de vales, associado ao desenvolvimento de rampas de alúvio-colúvio e terraços de acumulação. A segunda fase neotectônica corresponde ao regime extensional NW-SE, implantado no Holoceno médio, que exerceu um forte condicionamento estrutural nos canais fluviais, imprimindo rearranjos na rede de drenagem (Sarges, 2002).

A partir destas observações, ficou evidente que a movimentação tectônica extensional NW-SE foi responsável pela geração de falhamentos normais que promoveram desnivelamentos e basculamentos nos leitos dos canais tributários, funcionando como barragens e gerando, desta forma, os lagos.

Suguio \& Kohler (1992), identificaram para complexo lacustre do rio Doce a existência de aproximadamente 50 lagos e paleolagos, dos quais 21 seriam preenchidos por sedimentos, 25 em processo colmatação (siltation) e apenas 8 livres de sedimentação. Para estes autores a evolução dos lagos quaternários do PERD teria estreita relação com as mudanças paleoclimáticas e/ou neotectônicas, tendo os autores identificado a possibilidade de ocorrência de um rifte correspondendo ao local do Parque Estadual do Rio Doce.

\section{RESULTADOS}

\section{Descrição do testemunho LP-01}

A testemunhagem LP-01 recuperou integralmente os 200 cm perfurados com predomínio de sedimentos argilosos (Figura 2). A sequência sedimentar recuperada foi dividida em três fácies de argila, que variam na sua coloração, assim designadas da base para o topo: fácies de argila cinza claro (200-26 cm), fácies de argila cinza escuro (26-19,5 $\mathrm{cm})$ e, no topo, fácies de argila marrom $(19,5-0 \mathrm{~cm})$.

\section{Datação radiocarbônica}

Uma datação radiocarbônica foi realizada na base do testemunho, que acusou a idade de $6.620 \pm 110$ anos A.P., no Centro de Energia Nuclear na Agricultura/USP Piracicaba, São Paulo, Brasil.

\section{Distribuição dos grupos da matéria orgânica particulada}

Os resultados da distribuição quantitativa e da caracterização dos grupos da matéria orgânica particulada nas amostras estudadas estão sintetizados na Figura 2.

A matéria orgânica amorfa predomina sobre os demais componentes da matéria orgânica particulada em todas as amostras, ao longo do testemunho, representando, em média $81 \%$ do total da matéria orgânica particulada (Figura 3). Nas amostras analisadas, a MOA ocorre sob a forma de grumos ou dispersa, com coloração variando do castanho claro ao marrom. A MOA têm fluorescência constante ao longo da sequiência sedimentar, correspondente ao nível 3, de acordo com a escala de Tyson (1995).

O grupo dos fitoclastos opacos representa em média $3 \%$ do total de partículas. Dentre eles foi constatado o predomínio de elementos corroídos, de forma irregular e degradada e de elementos bioestruturados, que mostram a estrutura típica de tecidos vegetais, como lúmen celular, perfurações, etc., em relação aos alongados e equidimensionais.

Dentre os fitoclastos não-opacos a frequência de fitoclastos não-opacos não bioestruturados e dos fitoclastos não-opacos bioestruturados estriados foi maior em relação às membranas e cutículas. Ao todo os fitoclastos não-opacos representam, em média, 5,9\% do total de partículas. Os fitoclastos não-opacos têm fluorescência mais fraca, de coloração amarela escura a laranja, enquanto que as cutículas mostram fluorescência amarela clara.

Os palinomorfos identificados pertencem aos seguintes grupos: esporos de fungos (4,2\%); grãos de pólen (3,0\%); cianobactérias $(0,9 \%)$; esporos de pteridófitos $(0,7 \%)$ e algas $(0,5 \%)$. Os esporos de fungos aparecem com coloração marrom, isolados ou em agregados de grãos. Dentre os grãos de pólen há predominância de grãos de pólen porados, com os colporados e colpados como elementos subordinados. As cianobactérias, que mostram um hábito aparentemente colonial e filamentoso, apresentam menor distribuição no topo e na base do testemunho. As algas incluem Botryococcus braunii (Kützing, 1849) e Pediastrum sp. (Meyen, 1829), ambas com percentuais inferiores a $1,2 \%$, ao longo de todo o testemunho. 

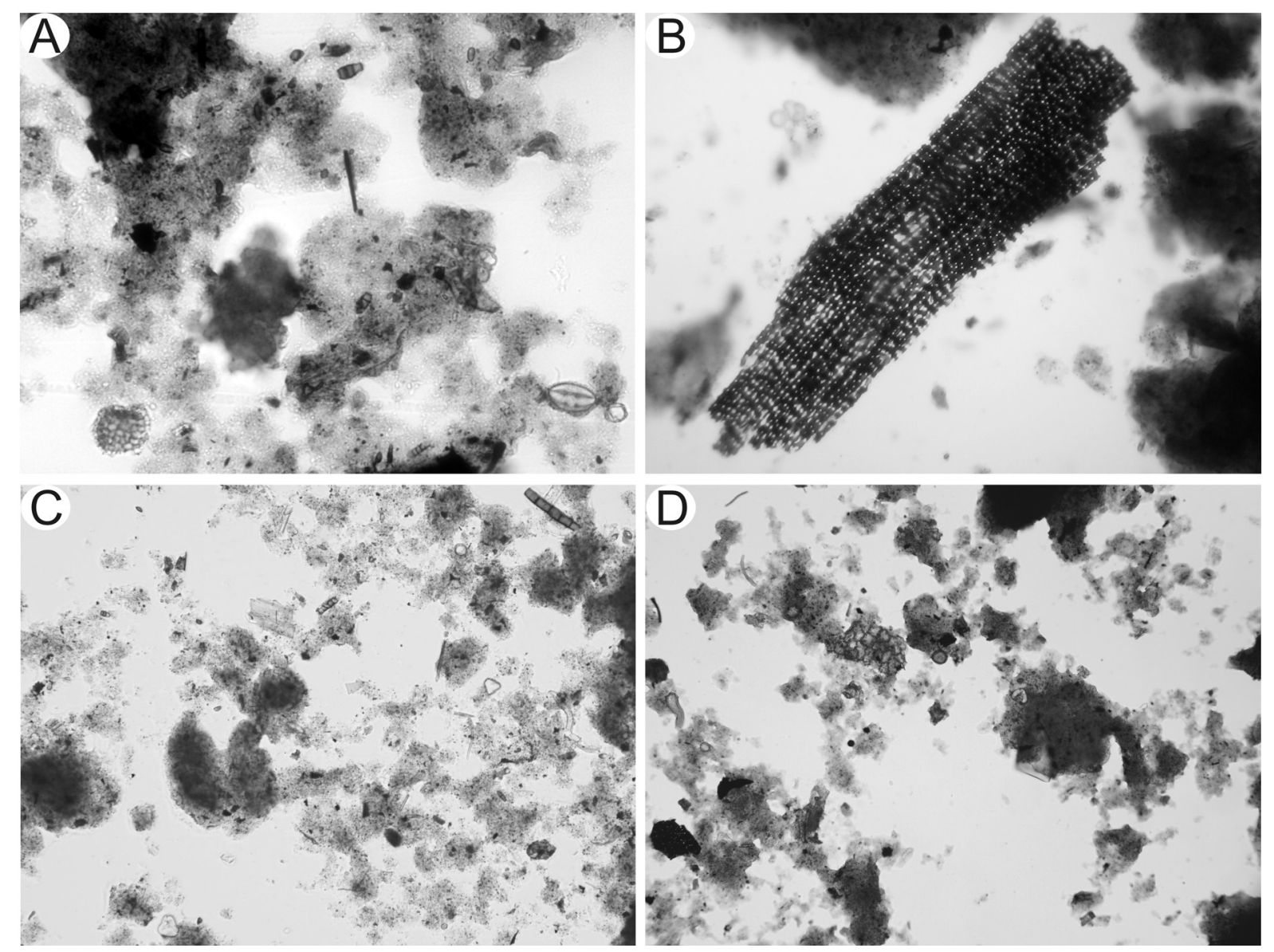

Figura 3. A,C-D, aspecto geral da palinofácies identificada, mostrando predomínio de matéria orgânica amorfa; B, fitoclasto não opaco bioestruturado. Sem escala.

Figure 3. A,C-D, overview of the identified palynofacies, showing a predominance of amorphous organic matter; B, non opaque biostructured phytoclasts. Not on scale.

\section{DISCUSSÃO}

\section{Palinofácies com predomínio de matéria orgânica amorfa como indicadora de ambientes disóxicos-anóxicos}

De acordo com a quantidade de matéria orgânica amorfa identificada nas diferentes palinofácies é possível caracterizar a existência de condições disóxicas a anóxicas na interface água sedimento no momento da deposição da matéria orgânica particulada. Esta interpretação está baseada no fato de que a alta porcentagem de matéria orgânica amorfa é característica de áreas de alta preservação devido a condições redutoras e de baixa energia, especialmente aquelas afastadas de áreas de atividade flúvio-deltaicas que estão associadas com processos de diluição por esporomorfos e fitoclastos (Tyson, 1995; Bustin, 1988).

A palinofácies identificada nos sedimentos do testemunho de sondagem LP-01, da lagoa Preta com predomínio de matéria orgânica amorfa-MOA (70-95\%), esporos de fungos e fitoclastos opacos como elementos subordinados nos permite sugerir que este lago apresentou condições disóxicasanóxicas, com pouca perturbação da interface água/sedimento de fundo. Por outro lado considerando que os estudos neotectônicos e sedimentares prévios na área do PERD (e.g.
Mello, 1997) mostraram um progressivo assoreamento do sistema de lagos, não se pode descartar a possibilidade de que a matéria orgânica do testemunho LP-01, possa ter sido depositada em ambiente paludal em processo de colmatação. Os baixos percentuais de algas suportam esta hipótese.

Em condições ambientais onde há deficiência de oxigênio (disóxica/anóxica), ocorre a preservação dos componentes lábeis, ricos em hidrogênio, que fluorescem quando expostos à excitação de luz azul ou ultravioleta. Desta forma, a intensidade e coloração da fluorescência da matriz de partículas amorfas heterogêneas pode ser medida através de padrões de intensidade de fluorescência. Como a matriz da matéria orgânica amorfa é mais facilmente oxidada, a resposta total da fluorescência, incluindo as inclusões de outros tipos de partículas orgânicas, vai refletir a natureza do plâncton e dos processos oxidativos do ambiente deposicional (Tyson, 1995).

Ao longo da sequência sedimentar da lagoa Preta, a MOA têm fluorescência constante, correspondente ao nível 3, de acordo com a escala de Tyson (1995). Segundo este autor, a fluorescência de nível 3 ocorre quando a maioria dos palinomorfos apresenta fluorescência e a matriz da matéria orgânica exibe coloração de fluorescência fraca.

Como variáveis importantes nos estudos 
paleolimnológicos podemos citar a quantidade de oxigênio (lagos eutróficos e oligotróficos) e a quantidade de nutrientes, disponível na lâmina d'água, que são alteradas pela mistura das massas d'água de superfície e de fundo controladas por fatores climáticos como alternância das estações e variações de temperatura.

De acordo com a quantidade de oxigênio e nutrientes disponíveis, os lagos são classificados em sistemas oligotróficos e/ou eutróficos. O lago oligotrófico constitui um sistema pouco produtivo onde a cadeia alimentar é pequena, com déficit de nutrientes; são lagos claros e com oxigênio disponível nas águas. O lago eutrófico é um sistema bastante produtivo que recebe aporte de nutrientes, são lagos escuros. Durante o processo de eutrofização, a quantidade de matéria orgânica aumenta, disponibilizando maior aporte de nutrientes, o fitoplâncton e o zooplâncton proliferam. O número de bactérias aumenta, o consumo de oxigênio é maior, caracterizando condições disóxicas/anóxicas (Schäfer, 1984).

Estudos limnológicos prévios apontam que os lagos do PERD (Dom Helvécio, Carioca e Jacaré) apresentam uma estratificação térmica na estação chuvosa $\left(30-33^{\circ} \mathrm{C}\right)$ e que a circulação vertical não se estende até o fundo na interface água-sedimento nem mesmo na estação seca quando a temperatura da água diminui a valores em torno de $22-26^{\circ} \mathrm{C}$ (Saijo \& Tundisi, 1997).

Períodos de longa estratificação nos lagos diminuem a quantidade de nutrientes, resultando alta produção de fitoplâncton no início deste período, num segundo momento a exaustão de nutrientes faz com que o fitoplâncton atinja valores mínimos. A maior parte da biomassa fica confinada ao metalimnion sendo decomposta pelas cianobactérias (Saijo \& Tundisi, 1997).

Para a lagoa Preta, o parâmetro estratificação térmica atual não pode ser mensurado porque esta lagoa não possui lâmina d'água nos dias de hoje. No entanto, a baixa disponibilidade de nutrientes e a consequente baixa produção de fitoplâncton como reflexo dos longos períodos de estratificação, pode estar refletida nos parâmetros medidos na análise de palinofácies já que a ocorrência de algas varia de 0 a $1,2 \%$.

\section{Fitoclatos como partículas que dispersam a matéria orgâni- ca particulada}

A presença de fitoclastos não-opacos no conjunto da matéria orgânica particulada indica condições óxicas, proximidade da fonte fluvial e entrada de sedimentos da borda através de enxurradas quando chove. Já os fitoclastros opacos apresentam maior resistência à degradação e permanecerão no ambiente deposicional após a destruição seletiva da maioria dos outros componentes da matéria orgânica particulada. Percentuais elevados de fitoclastos opacos estão associados a sedimentos de granulometria grossa, e, ambientes de alta energia (Tyson, 1993).

Apesar de ter sido identificada apenas uma palinofácies, foi constatada uma oscilação da frequência de matéria orgânica amorfa entre 70 e $90 \%$. Esta oscilação, diminuindo os valores de MOA, coincide com o aumento de fitoclastos opacos e não-opacos no ambiente deposicional.
No registro sedimentar da lagoa Preta não existem evidências da presença de sedimentos de granulometria grossa, que possam ser atribuídos ao aporte fluvial ou enxurradas. A presença dos fitoclastos não-opacos pode ser atribuída à degradação da vegetação da borda do corpo lacustre na lâmina d'água. Já o percentual significativo dos fitoclastos opacos pode ser atribuído a uma origem de incêndios naturais ou antrópicos, devido à presença de fitoclastos opacos bioestruturados.

\section{CONSIDERAÇÕES FINAIS}

A matéria orgânica particulada recuperada dos sedimentos associada ao predomínio de fácies de granulometria fina do testemunho de sondagem LP-01 da lagoa Preta, na área do Parque Estadual do Rio Doce, reflete um ambiente deposicional lacustre holocênico, depositado provavelmente por decantação, em ambiente lacustre ou paludal.

Este ambiente deposicional lacustre ou paludal representado pelos sedimentos argilosos da lagoa Preta, que foram depositados acima das fácies de aluvião do antigo leito do rio Doce, a partir de $6.620 \pm 110$ anos A.P. está associado à fácies que caracterizam a evolução do sistema lacustre holocênico, conforme identificado em trabalhos prévios em depósitos lacustres na área do PERD.

A partir da caracterização dos tipos de componentes orgânicos particulados e da correlação entre as variações de seus percentuais, foi possível identificar uma palinofácies com predomínio de matéria orgânica amorfa-MOA (70-95\%), esporos de fungo e fitoclastos opacos como elementos subordinados. Esta palinofácies mostrou uma oscilação da frequência de matéria orgânica amorfa entre 70 e $90 \%$. A diminuição da MOA coincide com o aumento de fitoclastos opacos e não-opacos. Provavelmente, a entrada dos fitoclastos dispersa a MOA propiciando a atividade do $\mathrm{O}_{2}$ na coluna d'água e/ou na interface água sedimento.

No que diz respeito às condições paleolimnológicas da lagoa Preta a análise de palinofácies nos permite concluir que: a sequiência sedimentar estudada apresentou condições anóxicas-disóxicas, compatíveis com lâmina d'água de pouca profundidade depositada em ambiente lacustre ou paludal, devido a grande quantidade de MOA e ausência significativa de algas como Botryococcus braunii (Kützing, 1849) e Pediastrum sp. (Meyen, 1829); e, que a lagoa Preta esteve, provavelmente, em processo assoreamento desde $6.620 \pm 110$ anos A.P.

Estudos limnológicos prévios nos lagos do PERD mostraram que atualmente os lagos apresentam uma estratificação térmica na estação chuvosa $\left(30-33^{\circ} \mathrm{C}\right)$, e que, a circulação vertical não se estende até o fundo na interface água-sedimento nem mesmo na estação seca $\left(22-26^{\circ} \mathrm{C}\right)$. Para a lagoa Preta o parâmetro estratificação térmica atual não foi mensurado porque esta lagoa não possui lâmina d'água nos dias de hoje. No entanto, a baixa disponibilidade de nutrientes e a consequente baixa produção de fitoplâncton como reflexo dos longos períodos de estratificação pode estar refletida nos parâmetros medidos na análise de palinofácies, já que a ocorrência de algas varia de 0 a $1,2 \%$. 


\section{AGRADECIMENTOS}

O primeiro autor agradece à Fundação de Amparo a Pesquisa do Estado de Minas Gerais-FAPEMIG, pela concessão de bolsa de iniciação científica. Os autores agradecem a Silvia Grill e ao revisor anônimo pelas sugestões que muito contribuíram para o aperfeiçoamento deste trabalho. Contribuição apresentada no XII SBPP (Florianópolis, 02 a 05 de novembro de 2008).

\section{REFERÊNCIAS}

Albuquerque, A.L.S. 1998. Paleoambientes holocênicos do Lago Dom Helvécio, Parque Florestal do Rio Doce, MG. Programa de Pós-Graduação em Geociências, Universidade Federal Fluminense, Tese de Doutorado, 120 p.

Barbosa, G.V. \& Kohler, H.C. 1981. O sistema lagunar do Parque Estadual do Rio Doce (MG). Boletim da Sociedade Brasileira de Geologia-MG, 2:37-46.

Bustin, R.M. 1988. Sedimentology and characteristics of dispersed organic matter in Tertiary Niger Delta: origin of source rocks in deltaic environment. Bulletin of the American Association of Petroleum Geologists, 72:277-298.

Combaz, A. 1964. Les palynofacies. Revue de Micropaléontologie, 7:205-218.

Heineck, C.A. 2003. Mapa Geológico do Estado de Minas Gerais, 1:1.000.000. Convênio COMIG/CPRM, 1 folha.

Mello, C.L. 1997. Sedimentação e tectônica cenozóicas no Médio Vale do Rio Doce (MG, sudeste do Brasil) e suas implicações na evolução de um sistema de lagos. Instituto de Geociências, Universidade de São Paulo, Tese de Doutorado, 275 p.

Mendonça Filho, J.G. 1999. Aplicação de estudos de palinofácies e fácies orgânica em rochas do Paleozóico da Bacia do Paraná, Sul do Brasil. Programa de Pós-Graduação em Geociências, Universidade Federal do Rio Grande do Sul, Tese de Doutorado, $338 \mathrm{p}$.

Mendonça Filho, J.G.; Carvalho, M.A. \& Menezes, T.R. 2002. Palinofácies: In: T.L. Dutra (org.) Técnicas e procedimentos de trabalho com fósseis e formas modernas comparativas, Editora Unisinos, p.20-24.

Menezes, T.R. 2002. Aplicação de parâmetros palinofaciológicos e organogeoquímicos na reconstrução paleoambiental do talu- de continental brasileiro recente na Bacia de Campos, RJ. Programa de Pós-Graduação em Geologia, Universidade Federal do Rio de Janeiro, Dissertação de Mestrado, 174 p.

Menezes, T.R.; Mendonça Filho, J.G.; Araújo, M.C.; Souza, I.V.A.F. \& Mendonça, J.O. 2008. Fácies orgânica: conceitos, métodos e estudos de casos na indústria do petróleo. Revista Brasileira de Geociências, 38(2-suplemento):1-17.

Meyer, K.E.B.; Mendonça Filho, J.G.; Ashraf, A.R.; Souza, P.A.; \& Reichhart, K. 2005. Análise de palinofácies em sedimentos holocênicos da lagoa dos Quadros, Rio Grande do Sul, Brasil. Revista Brasileira de Paleontologia, 8(1):57-72.

Meyer, K.E.B.; Souza, P.A.; Cwik, M.R.; Menezes, T.R. \& Buchmann, F.S. 2006. Palinofácies e processos deposicionais em sedimentos de fundo da lagoa dos Quadros, planície costeira do Rio Grande do Sul, Brasil. Revista Brasileira de Geociências, 36(4):569-576.

Saadi, A. 1991 Ensaio sobre a morfotectônica de Minas Gerais. Instituto de Geociências, Universidade Federal de Minas Gerais, Tese Professor Titular, 285 p.

Saijo, Y. \& Tundisi, J.G. 1997. Synthesis: limnological studies on the Rio Doce Valley Lakes. In: J.G. Tundisi \& Y. Saijo (orgs.) Limnological studies on the Rio Doce Valley Lakes, Brazil. Academia Brasileira de Ciências/USP, p. 485-491.

Sarges, R.R. 2002. Morfologia de lagos da região médio vale do rio Doce, Minas Gerais, e sua relação com a tectônica quaternária. Programa de Pós-Graduação em Geologia, Universidade Federal do Rio de Janeiro, Dissertação de Mestrado, 188 p.

Schäfer, A. 1984. Fundamentos de ecologia e biogeografia das águas continentais. Porto Alegre, Editora da Universidade Federal do Rio Grande do Sul, 532 p.

Suguio, K. \& Kohler, H.C. 1992. Quaternary barred lake systems of the Doce River (Brazil). Anais da Academia Brasileira de Ciências, 64(2):183-191.

Traverse, A. 1994. Sedimentation of palynomorphs and palynodebris: an introduction. In: A. Traverse (ed.) Sedimentation of Organic Particles, Cambridge University Press, p. 1-8.

Tyson, R.V. 1993. Palynofacies analysis. In: D.G. Jenkins (ed.) Applied micropaleontology, Kluver Academic Publishers, p. 153-191.

Tyson, R.V. 1995. Sedimentary organic matter: organic facies and palynofacies analysis. London, Chapman \& Hall, 615 p.

Received in January, 2009; accepted in January, 2010. 